\title{
The $U$ br 2 gene is expressed in skeletal muscle atrophying as a result of hind limb suspension, but not Mergla expression alone
}

\author{
Gregory H. Hockerman (1), Nicole M. Dethrow (2), Sohaib Hameed (2), Maureen Doran (2), \\ Christine Jaeger (3), Wen-Horng Wang (1), Amber L. Pond (1,2) \\ (1) Medicinal Chemistry and Molecular Pharmacology, School of Pharmacy, Purdue \\ University, West Lafayette, IN, USA; (2) Anatomy Dept., Southern Illinois University School of \\ Medicine, Carbondale, IL, USA; (3) Basic Medical Sciences, School of Veterinary Medicine, \\ Purdue University, West Lafayette, IN, USA
}

\begin{abstract}
Skeletal muscle (SKM) atrophy is a potentially debilitating condition induced by muscle disuse, denervation, many disease states, and aging. The ubiquitin proteasome pathway (UPP) contributes greatly to the protein loss suffered in muscle atrophy. The MERG1a $\mathrm{K}^{+}$channel is known to induce UPP activity and atrophy in SKM. It has been further demonstrated that the mouse ether-a-gogo-related gene (Merg) 1a channel modulates expression of MURF1, an E3 ligase component of the UPP, while it does not affect expression of the UPP E3 ligase Mafbx/ATROGIN1. Because the UBR2 E3 ligase is known to participate in SKM atrophy, we have investigated the effect of Mergla expression and hind limb suspension on Ubr2 expression. Here, we report that hind limb suspension results in a significant $25.6 \%$ decrease in mouse gastrocnemius muscle fiber cross sectional area (CSA) and that electro-transfer of Merg 1 a alone into gastrocnemius muscles yields a $15.3 \%$ decrease in CSA after 7 days. More interestingly, we discovered that hind limb suspension caused a significant 8 -fold increase in Merg $1 a$ expression and a significant 4.7-fold increase in $U b r 2$ transcript after 4 days, while electro-transfer of Mergla into gastrocnemius muscles resulted in a significant 6.2-fold increase in Mergla transcript after 4 days but had no effect on Ubr2 expression. In summary, the MERG1a $\mathrm{K}^{+}$channel, known to induce atrophy and MURF1 E3 ligase expression, does not affect UBR2 E3 ligase transcript levels. Therefore, to date, the MERG1a channel's contribution to UPP activity appears mainly to be through up-regulation of Murfl gene expression.
\end{abstract}

Key Words: Skeletal muscle atrophy; UBR2; E3 $\alpha$-II; ERG1a potassium channel; hind limb suspension; E3 ligase; ubiquitin proteasome pathway

Eur J Trans Myol - Basic Appl Myol 2014; 24 (3): 173-179

Skeletal muscle (SKM) can comprise $30-50 \%$ of body weight in humans and it functions in body movement, maintenance of posture and balance, soft tissue support, bolster of body entry and exit points and in temperature regulation. The loss of SKM mass and strength is referred to as atrophy and is known to result from unweighting, injury, denervation, disuse, disease (e.g., diabetes, cancer, etc.) and aging. ${ }^{1-5}$ Atrophy occurs when there is an imbalance in the processes of protein synthesis and protein degradation that favors protein loss. Numerous cellular pathways can contribute to SKM atrophy, including calpains, cathepsins and the ubiquitin proteasome pathway (UPP). ${ }^{2,4}$ The UPP is reported to be responsible for as much as $75 \%$ of the protein degradation that occurs during SKM atrophy ${ }^{2,4,6}$ It is composed of three basic enzymes: E1 proteins which activate ubiquitin; E2 ubiquitin-conjugating molecules which accept the activated ubiquitin and interact with specific E3 enzymes; and the E3 ligase which binds target protein molecules and catalyzes the transfer of the ubiquitin from E2 to the E3-bound protein. ${ }^{7,8}$ A minimum of four ubiquitin molecules are required to be ligated to the target protein before it is degraded by the $26 \mathrm{~S}$ proteasome. To date, only a few members of the E1 family have been identified (only two E1 enzymes have been detected within the human proteome) and over 50 E2 enzymes have been reported; however, several hundred potential E3 ligases have been described within mammalian genomes. Two main types of E3 enzymes have been described: the "homologous with E6-associated protein C6 terminus" (HECT) domain enzymes and the larger family of 


\section{Hind Limb Suspension, but not Merg1a, Yields $\boldsymbol{U} b r 2$ Expression}

Eur J Trans Myol - Basic Appl Myol 2014; 24 (3): 173-179

"really interesting new gene" (RING) finger scaffold proteins. A newer described group of proteins with ubiquitin ligase activity, having atypical RING finger moieties, ${ }^{9}$ have been described and are often referred to as E4 enzymes. These have been reported to work in concert with $\mathrm{E} 3$ proteins to enhance their activity. ${ }^{10}$ A number of E3 ligases have been identified as contributors to atrophy in SKM. Muscle ring finger-1 (MURF1) and Muscle Atrophy F-box $(M a f b x) / A T R O G I N 1$ are RING finger E3 ligases specific to striated muscle that have been detected in several models of SKM atrophy, including unweighting, and are considered markers of atrophy. ${ }^{1,2,4}$ Ubiquitin ring-type (UBR, also referred to as E3 $\alpha$ ) proteins are RING finger E3 ligases that are also reported to function in atrophic SKM, specifically cachexia-induced atrophy. ${ }^{11}$ The UBR box family of RING finger E3 ubiquitin ligases is composed of enzymes which recognize substrate proteins that have an N-degron; that is, the protein to be degraded has: 1) a destabilizing $\mathrm{N}$-terminal residue; and 2) an internal lysine residue for ubiquitination. ${ }^{7,12,13}$ These enzymes are often referred to as $\mathrm{N}$-recognins and this pattern of protein degradation, referred to as the $\mathrm{N}$-end rule pathway, relates the identity of the $\mathrm{N}$-terminal amino acid of a protein to its half-life in vivo ${ }^{7,13,14}$ UBR1 (also E3 $\alpha-I)$ was the first E3 ligase implicated in SKM atrophy ${ }^{14,15}$ and is believed to bind proteins that commence with unblocked hydrophobic or basic amino acids. ${ }^{7,16-19}$ The UBR2 (also E3 $\alpha$-II) member of the UBR family was described by Varshavsky and coworkers. ${ }^{17}$ In 2004 , Kwak et al. demonstrated that both the $U b r l$ and 2 homologues are up-regulated in the atrophying SKM of rats bearing malignant tumors. ${ }^{11}$ However, it was concluded that the UBR2 isoform is more critically involved in the process because it is more specifically expressed in SKM tissue and is detected at the early onset of atrophy while UBR1 is not. In fact, a recent study suggests that tumor cellinduced up-regulation of $U b r 2$ expression in skeletal muscle may be mediated by the $\mathrm{p} 38 \beta-\mathrm{C} / \mathrm{EBP} \beta$ signaling pathway. ${ }^{19}$

The ether-a-gogo- related gene (ERG) $1 \mathrm{a} \mathrm{K}^{+}$channel is known to be partially responsible for late phase repolarization of the cardiac action potential in many mammalian species, including mice and humans. ${ }^{21}$ Our laboratory has demonstrated that this channel is upregulated in the SKM of mice experiencing atrophy as a result of both hind limb suspension (unweighting) and cancer cachexia. ${ }^{22}$ Further, we have demonstrated that electro-transfer of Mergla alone into the SKM of weight bearing mice induces atrophy and, importantly, that electro-transfer of Mergla into mouse SKM upregulates UPP activity. More recently, we have shown that electro-transfer of Mergla into mouse SKM up- regulates the expression of the E3 ligase Murfl, but not Mafbx/ATROGIN1. ${ }^{22}$ Because of its link to atrophy with both unweighting and cachexia, we asked if Mergla expression would also modulate expression of the Ubr2 E3 ligase gene. Here, we have determined the time course of Mergla and Ubr2 expression in response to both hind limb suspension and electrotransfer of the Mergla $\mathrm{K}+$ channel and show that, although $U b r 2$ is expressed in response to hindlimb suspension, its expression is not modulated by Mergla expressed alone.

\section{Materials and Methods}

Animals. The Purdue Animal Care and Use Committee approved all procedures. ND4-Swiss Webster male mice at 8 weeks age (Harlan-Sprague; Indianapolis, IN) were used in all procedures. Animals were provided food and water ad libitum, housed in Purdue University animal facilities on a 12 hour light/dark cycle and monitored by lab animal veterinarians. At completion of all studies, anesthetized animals were humanely killed according to the approved protocol prior to harvest of the gastrocnemius muscles (GMs).

Hind Limb Suspension. Custom suspension cages were assembled as described earlier. ${ }^{23}$ Animals were positioned in these cages resting in an approximate $30^{\circ}$ head down tilt with their hind limbs raised off of the floor so that they were unable to place any weight on them. Commercial mouse cages were used to house control mice in a natural weight bearing state.

Tissue Sectioning, Staining and CSA Determination. GMs were embedded using OCT $^{\mathrm{TM}}$ (Electron Microscopy Sciences; Hatfield, PA), cryo-sectioned (12 $\mu \mathrm{m})$ and stained for $\beta$-galactosidase (LACZ) activity as described previously. ${ }^{21}$ Images of sections were captured with a Leaf Micro-Lumina digital camera (Scitex; Tel-Aviv, Israel). The CSA $\left(\mu \mathrm{m}^{2}\right)$ of each muscle fiber was determined using a micrometer slide and Image $\mathbf{J}$ software (NIH; Bethesda, MD).

Plasmids. The Mergla clone in $\mathrm{pBK} / \mathrm{CMV}^{24}$ was a generous gift from Dr. Barry London (Cardiovascular Institute, University of Pittsburgh, PA). The CMVlacZ in $\mathrm{pNL}$ vector was purchased from the Center Commercial de Gros (Toulouse, France).

Electro-transfer. Mice were anesthetized using $10 \mu \mathrm{l} / \mathrm{g}$ body weight of xylazine $(1 \mathrm{mg} / \mathrm{ml})$ and ketamine $(9$ $\mathrm{mg} / \mathrm{ml}$ ) in sterile saline according to an approved protocol. Hind limbs were shaved and the both GMs were injected with expression plasmid (see Study 2 below) in $50 \mu \mathrm{l}$ sterile saline. Eight electrical pulses at $200 \mathrm{~V} / \mathrm{cm}$ for $20 \mathrm{~ms}$ at $1 \mathrm{Hertz}$ were applied to all lower limbs (GMs) with an ECM 830 ElectroSquare Porator (BTX; Hawthorne, NY). This method results in gene transcription and translation in SKM in our laboratory. ${ }^{22,23,25}$ 
Hind Limb Suspension, but not Merg1a, Yields Ubr2 Expression

Eur J Trans Myol - Basic Appl Myol 2014; 24 (3): 173-179
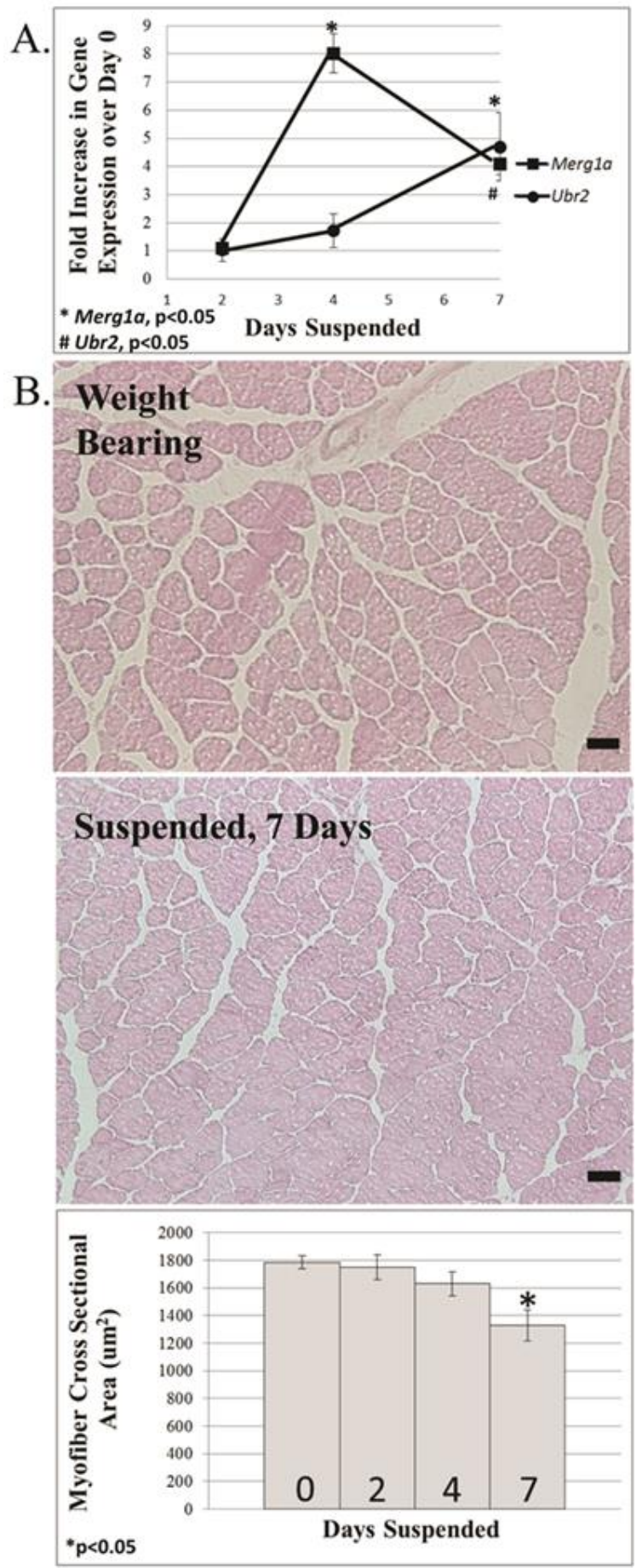

Figure 1. Hind limb suspension causes SKM atrophy and up-regulation of both Mergla and Ubr2 E3 ligase expression.

Real Time PCR. Trizol reagent (Invitrogen; Carlsbad, CA) was used to extract total RNA from GMs according to manufacturer's instructions. Phenol/chloroform extraction and ethanol precipitation sequentially followed the extraction. Contaminating DNA was degraded by two $10 \mathrm{~min}$ treatments with
DNase I (ProMega; Madison, WI) and the DNase was subsequently heat inactivated. A GoScript ${ }^{\mathrm{TM}}$ Reverse Transcriptase Kit (ProMega; Madison, WI) was used to reverse transcribe cDNA using an Eppendorf Mastercycler Personal (Hauppauge, NY). PerfeCTa SYBR Green Supermix for iQ (Quanta Biosciences, Inc.; Gaithersberg, MD) was added to the PCR reaction (per manufacturer's instructions) and primers (see Table 1) for the gene of interest were added to the samples (in triplicate) while primers for an appropriate "housekeeping" gene (the $18 \mathrm{~S}$ ribosomal subunit) were added to identical samples (in triplicate). A BioRad MyiQ single Color Real time PCR Detection System (BioRad; Hercules, CA) was used to detect SYBR Green fluorescence as a measure of amplicon. Sample CT values were normalized to (subtracted from) the CT values of the $18 \mathrm{~S}$ "housekeeping" gene and the number 2 was raised to a power equal to the difference between the sample CT values of the $18 \mathrm{~S}$ subunit and the gene of interest. ${ }^{22,23,25}$

Study 1 Experimental Design. Three groups of five mice each were hindlimb suspended ${ }^{22}$ for either 2,4 or 7 days. A fourth group of five mice were allowed to remain weight bearing and were used as day 0 controls $(n=20)$. After the assigned control or suspension duration, each group of mice was killed according to the approved protocol and the GMs were harvested and flash frozen in liquid nitrogen. The left GMs from all mice were prepared for real time PCR and thus assayed for expression of Mergla and Ubr2 genes (see above). Normalized sample CT values for the Day 0 control were averaged and the fold increase in gene expression for each gene per mouse was determined by calculating the ratio of each daily mouse sample gene expression value to the average Day 0 value.

Study 2 Experimental Design. All GMs of 20 mice (4 groups of 5 each) were injected with $10 \mu \mathrm{g} \mathrm{LacZ}$ and $20 \mu \mathrm{g}$ Mergla expression plasmid and were subjected to electro-transfer as described above. A group of 5 mice each was killed at days 0, 2, 4 and 7 after electrotransfer $^{22,23,25}$ and the GMs from all legs were harvested and flash frozen in liquid nitrogen. The GMs from the left legs were cryo-sectioned and stained for LACZ activity as a marker for gene expression while right legs were prepared for real time PCR as described above. Because a greater abundance (2X) of Mergla than $L a c Z$ expression plasmid was injected, we assume that all myofibers staining for LACZ reporter activity also express Mergla and that those myofibers not staining for LACZ activity are not expressing plasmid. Statistics. Data were analyzed by ANOVA using a completely randomized design. When significant differences were found, means were separated by Fisher's Protected Least Significant Difference. All data were analyzed using the General Linear Model Procedure of SAS (SAS Institute Inc.; Cary, NC). All statements of significance are $\mathrm{p} \leq 0.05$. 


\section{Hind Limb Suspension, but not Merg1a, Yields Ubr2 Expression}

Eur J Trans Myol - Basic Appl Myol 2014; 24 (3): 173-179

\section{Results and Discussion}

Study 1. Hind limb suspension causes SKM atrophy and up-regulation of both Mergla and Ubr2 E3 ligase expression.

Similar to earlier studies conducted in our laboratory, ${ }^{22}$ hindlimb suspension caused decreases in myofiber CSA at Day $2(2 \%)$ and Day $4(8.7 \%)$, but the decreases are not statistically significant (Figure 1B). The $25.6 \%$ decrease at Day 7 , however, is statistically significant. Also, similar to other studies we have conducted, ${ }^{23}$ hind limb suspension does not result in a statistically significant increase in Mergla $\mathrm{K}^{+}$channel expression at Day 2; however, it does result in a significant 8-fold increase in the expression of the Mergla $\mathrm{K}^{+}$channel by Day 4 (Figure 1A). The level of Mergla $\mathrm{K}^{+}$channel transcript decreases from that of Day 4 by Day7 although it remains significantly higher (4.1 fold) than Day 0.

Study 2. Ectopic expression of the Mergla $K+$ channel gene induces atrophy, but not expression of the gene encoding the Ubr2 E3 ligase. Reminiscent of earlier work in our laboratory, ${ }^{22}$ myofiber CSA drops by $3.1 \%$ (Figure 2B) after 4 days of Merg la ectopic expression. Myofiber CSA drops by a statistically significant $15.3 \%$ after seven days of Mergla expression, demonstrating that Mergla expression induces SKM atrophy. In response to injection of Mergla expression plasmid into GM followed by electro-transfer, Mergla transcript is produced as shown earlier. ${ }^{22,23,25}$ Levels of this transcript increase 1.7-fold by Day 2 and then to a statistically significant higher 6.2 fold level by Day 4 . The Mergla transcript level drops by day 7, but is still a significant 3.8 fold higher than it was at Day 0 (Figure 2A). In contrast, Ubr2 gene expression does not increase in response to ectopic Mergla gene expression. SKM atrophy occurs as a result of an imbalance in protein synthesis and protein degradation which ultimately favors protein loss and muscle deterioration. The UPP, comprised of E1, E2 and E3 enzymes, is reported to be responsible for a large portion of the protein degradation that occurs in atrophying muscle. ${ }^{1-6}$ The E3 ligases MURF1 and Mafbx/ATROGIN1 are ring finger E3 ligases specific to striated muscle which contribute greatly to skeletal muscle atrophy induced by numerous factors. ${ }^{1-4}$

Our laboratory reported that the Mergla $\mathrm{K}^{+}$channel is expressed at high levels in the GMs of mice experiencing atrophy as a result of both hind limb suspension and cancer cachexia while it is basically undetected in the matched muscles of appropriate control animals. ${ }^{22} \mathrm{We}$ have also shown that the atrophy resulting from hind limb suspension can be inhibited by ectopic expression (resulting from electro-transfer) of the dysfunctional Mergla mutant, DN-Mergla, in the GMs as well as by treatment with astemizole, a known pharmacological ERG1 channel blocker. Further, electro-transfer of the Mergla $\mathrm{K}^{+}$channel
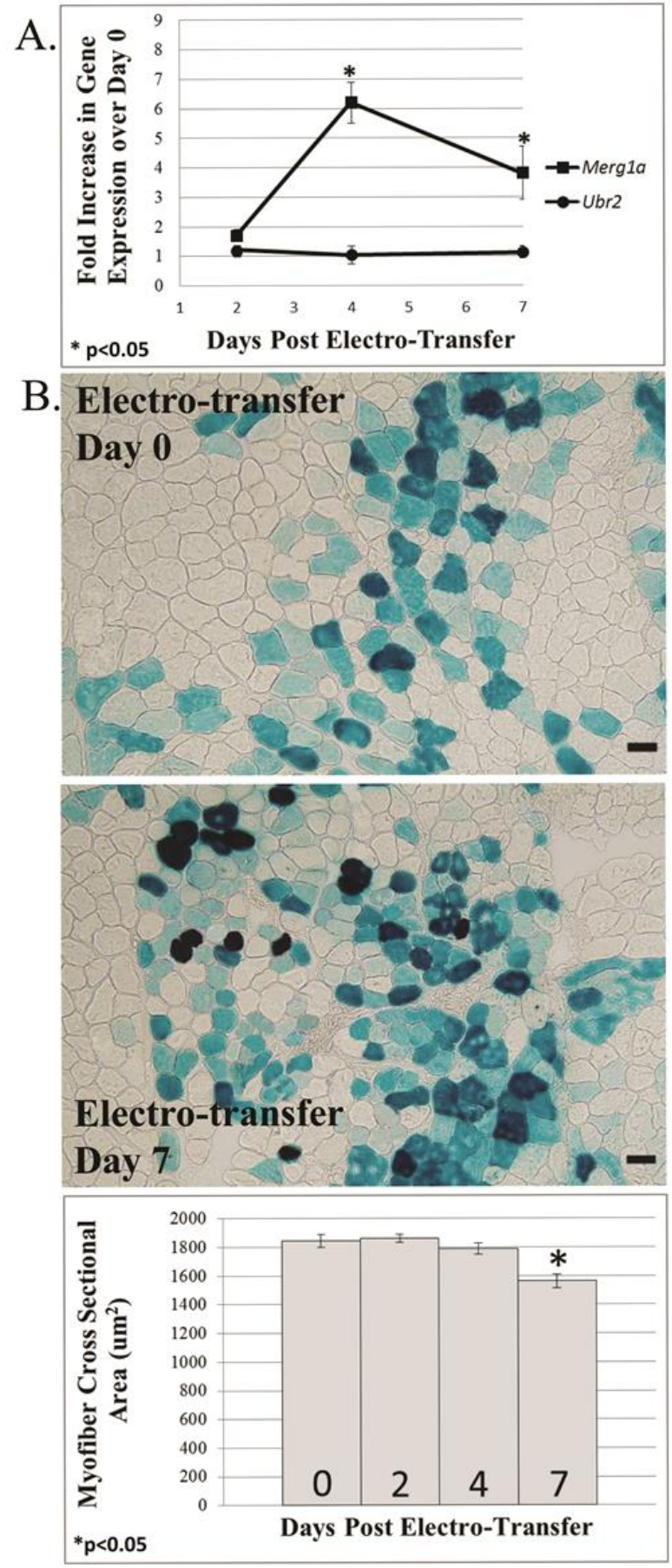

Figure 2. Ectopic expression of the Mergla K+ channel gene induces atrophy, but not expression of the gene encoding the Ubr2 E3 ligase.

gene into mouse GM induces atrophy and, importantly, increases UPP activity. ${ }^{22}$ The mechanism(s) by which MERG1a modulates UPP activity is not known; however, we recently demonstrated that Mergla expression does not modulate expression of 


\section{Hind Limb Suspension, but not Merg1a, Yields $\boldsymbol{U} b r 2$ Expression}

Eur J Trans Myol - Basic Appl Myol 2014; 24 (3): 173-179

Mafbx/ATROGIN1, although it does indeed increase the levels of both MURF1 transcript and protein. ${ }^{23}$ This separation of MURF1 and Mafbx/ATROGIN1 modulation at the level of a membrane protein is most interesting. Because the literature reports that Murfl transcription, and not that of $M a f b x$, is increased by $N F-\kappa B$ factors ${ }^{26}$ and that NF- $\kappa \mathrm{B}$ is basically required for disuse muscle atrophy ${ }^{26-28}$ this separation of E3 ligase modulation suggests that MERG1a may be modulating Murfl expression through NF- $\mathrm{BB}$ activity. Indeed, a study by Wang et al. (2002), reveals that cells expressing HERG have higher endogenous levels of the active form of NF- $\mathrm{KB}$ than those cell lines with little to non-detectable levels of endogenous HERG. ${ }^{29}$ Certainly these findings beg for further exploration into the potential effect of MERG1a on the NF- $\kappa B$ family of transcription factors (likely through the IKK$\beta / \mathrm{I} \kappa \mathrm{B}-\alpha / \mathrm{NF}-\kappa \mathrm{B}$ pathway) as well as the potential modulation of FOXO1 and 4 transcription factors (potentially through the PI3K/AKT/FOXO pathway). ${ }_{1,4,26,30}$ Obviously, the MERG1a $\mathrm{K}^{+}$channel may also interact with other known or unknown pathways. Our data show that hind limb suspension decreases mouse GM CSA by $25.6 \%$ while ectopic Mergla expression alone induces an approximately $10 \%$ lower $(15.3 \%)$ decline in GM CSA. This demonstrates that Mergla expression and the consequences of this channel up-regulation are not solely responsible for SKM atrophy. Indeed, we have already shown that Mergla expression does not induce expression of Mafbx/Atrogin1, ${ }^{23}$ an E3 ligase known to be responsible for a large percentage of SKM atrophy induced by immobilization, ${ }^{30}$ although it does induce expression of $M u R F 1,{ }^{23}$ another E3 ligase important to immobilization induced SKM atrophy. ${ }^{30}$ To further explore the potential effects of Mergla expression on SKM and its contributions to the atrophic process, we decided to determine if a member of the UBR family of ligases, known to be involved in SKM atrophy, is modulated by MERG1a. The UBR1 and UBR2 E3 ligases are two members of the UBR family (recently described as having 7 constituents) which are known to recognize substrate proteins having a destabilizing $\mathrm{N}$ terminal residue and an internal lysine residue for ubiquitin conjugation. ${ }^{31}$ Expression of these E3 ligases is induced in skeletal muscle undergoing atrophy as a result of cancer cachexia, although $U b r 2$ is upregulated earlier in the atrophic time course and also more dramatically and more specifically than $U b r l .^{20}$ In fact, $U b r 2$ up-regulation in the GMs of mice bearing malignant tumors is reported to occur within the time frame during which Mergla expression is highest in both suspended mice and in those expressing Mergla as a result of electro-transfer (during the first 7 days). The reported $U b r l$ expression time frame for cachectic mice (second week) does not correlate well with the Mergla expression time courses we have reported for either hind limb suspended or mice ectopically expressing Mergla. ${ }^{23}$ The existing data suggest that Mergla levels would be low when Ubrl levels are demonstrated to begin to increase, so that the increase in $U b r l$ transcript levels would not likely be a direct result of Merg la expression.

Although, it is possible that the time course for Mergla expression is more drawn out in mice experiencing muscle atrophy as a result of cancer cachexia, we nonetheless designed Ubr2 specific primers and monitored the time course of Ubr2 expression in response to both hind limb suspension and electro-transfer of Mergla into the GMs of mice. We discovered that, although hind limb suspension does induce transcription of both Mergla and Ubr2 within seven days of suspension, Mergla expression alone is not sufficient to yield increased levels of $U b r 2$ transcript within this time frame. One might speculate that the electro-transfer of Mergla into GMs needs additional time for insertion of this $\mathrm{K}^{+}$channel into the plasma membrane and physiological activation. However, our earlier work, ${ }^{22,23}$ demonstrated that the time frame applied (7 days post electro-transfer of Mergla) does indeed produce both transcription (rtPCR) and translation (western blotting) of the Mergla construct and a statistically significant $16 \%$ $(\mathrm{p}<0.05)$ decrease in GM CSA. We also have shown that this decrease in CSA can be inhibited by coelectro-transfer and co-expression of Mergla and a dominant negative (i.e., dysfunctional pore mutant) form of the Mergla channel 7 days after electrotransfer into skm. ${ }^{22}$ The inhibition of Mergla-induced atrophy by this dysfunctional pore mutant demonstrates that the electro-transferred Mergla $\mathrm{K}^{+}$ channel is functional. Further, we have shown that both pharmacological treatment of mice with an ERG channel pore blocker (oral gavage with astemizole) and electro-transfer of the dominant negative Mergla into GM of hind limb suspended mice inhibited atrophy (i.e., inhibited the decrease in muscle fiber $\mathrm{CSA}^{22}$ ). This evidence demonstrates (albeit indirectly) that the MERG1a channel is functional (located in the membrane and conducting current) within 7 days of electro-transfer. Therefore, it appears that Mergla expression alone does not affect expression of $\mathrm{Ubr} 2$ within 7 days; nonetheless, it is still feasible that an even longer post electro-transfer time frame may be necessary for adequate activation of the MERG1a channel to induce $U b r 2$ transcription. Further, this work does not rule out the possibility that MERG1a may affect or interact with some other factor produced during hind limb suspension which induces or participates in the induction of $U b r 2$ expression. For example, HERG protein and current expression is known to be regulated by kinases such as stressresponsive serum- and glucocorticoid-inducible kinase isoforms SGK1 and 3 in HEK cells, ${ }^{32}$ protein kinase 


\section{Hind Limb Suspension, but not Merg1a, Yields $\boldsymbol{U} b r 2$ Expression}

Eur J Trans Myol - Basic Appl Myol 2014; 24 (3): 173-179

$\mathrm{A}^{33}$ and AMP-dependent protein kinase (AMPK; 1). It is possible that such a factor(s) is necessary to modulate channel activity and produce atrophy and, although present during hindlimb suspension, is not present when Mergla is electro-transferred into muscle. We also must consider that the electro-transfer itself could interfere with the presence or production of some factor necessary for MERG1a-induced $U b r 2$ transcription, although we have not produced or read any evidence of this. Of course, even though we have shown that our system of Mergla electro-transfer into mouse GMs will induce transcription of significant levels of Mergla and the MuRF1 E3 ligase, ${ }^{22,23}$ the simplest issue may be that it may not have produced the levels of MERG1a necessary to induce $U b r 2$ transcription.

Finally, our work does not rule out the possibility that MERG1a may affect $U b r 2$ expression in muscle atrophying as a result of cancer cachexia. Previous studies support the existence of potential cellular connections between UBR2 and ERG. For example, $U b r 2$ expression is reported to activate the proinflammatory cytokine tumor necrosis factor-alpha (TNF- $\alpha$ ), which is involved in the onset of cachexia; ${ }^{11,29}$ and, interestingly, TNF- $\alpha$ stimulation of TNF receptor 1 (TNFR1) has been shown to impair human ERG (HERG)/IKr current density (and prolong action potential duration) by stimulation of reactive oxygen species in canine cardiomyocytes. ${ }^{33}$ Is it possible that TNF- $\alpha$ binds its receptor and affects ERG in such a way as to affect $U b r 2$ expression? Work by Wang et al., (2002) demonstrates that TNF- $\alpha$ affects cell growth and apoptosis more stringently in cells expressing ERG than those that do not, suggesting that TNFR1 may be more abundant in the ERG-expressing cells. ${ }^{34}$ Further, it is reported that cells positive for endogenous ERG protein also contained more abundant TNFR1 than cells that did not express high levels of endogenous ERG, suggesting that perhaps ERG channels somehow recruit TNFR1 to the cell membrane. Indeed, the same study showed that HERG and TNFR1 co-immunoprecipitate from cell lysates. ${ }^{34}$ Therefore, it does seem reasonable to suggest that, although Mergla expression alone may not induce $U b r 2$ expression, it may do so as a result of some missing factor that may be more significantly abundant under physiological atrophy producing conditions.

To our knowledge, this is the first report of an increase in $U b r 2$ expression in SKM as a response to disuse atrophy and also the first exploration of possible modulation of $U b r 2$ E3 ligase expression by MERG1a. We conclude that, although hind limb suspension of mice induces an increased expression of genes encoding Mergla and Ubr2 in GMs, the electrotransfer (and subsequent expression) of Mergla alone into GMs of mice does not affect expression of $\mathrm{Ubr} 2$ within 7 days of electro-transfer. The data suggest that either Merg 1 a does not affect $U b r 2$ expression or that, if it does, then it either needs more than 7 days to induce this expression or it must have access to another factor, one induced by conditions produced during skeletal muscle atrophy resulting from disuse and/or cancer cachexia.

\section{Acknowledgements}

The authors wish to thank Dr. Barry London (Cardiovascular Institute, Univ. of Pittsburgh, PA) for his generous gifts of the mERG1a and DN-mERGla clone in pBK/CMV. Research reported in this publication was supported by the National Institute of Arthritis and Musculoskeletal and Skin Diseases of the National Institutes of Health under Award Number NIH NIAMS 1R03AR053706-01A2 to ALP. The content is solely the responsibility of the authors and does not necessarily represent the official views of the National Institutes of Health.

\section{Corresponding Author}

Amber Pond, Anatomy Dept., Southern Illinois University School of Medicine, 2080 Life Sciences III, 1135 Lincoln Drive, Carbondale, IL 62901. Phone: 618-453-1582; FAX: 618-453-1527.

E-mail: apond@siumed.edu

\section{References}

1. Foletta VC, White LJ, Larsen AE, et al. The role and regulation of MAFbx/atrogin-1 and MuRF1 in skeletal muscle atrophy. Pflugers Arch-Eur J Physiol 2011;461:325-35.

2. Goodman CA, Mayhew DL, Hornberger TA. Recent progress toward understanding the molecular mechanisms that regulate skeletal muscle mass. Cell Signal 2011;23:1896-906.

3. Gumucio JP, Mendias CL. Atrogin-1, MuRF-1, and sarcopenia. Endocrine 2013;43:12-21.

4. Kandarian SC, Jackman RW. Intracellular signaling during skeletal muscle atrophy. Muscle Nerve 2006; 33:155-65.

5. Lecker SH, Solomon V, Mitch WE, Goldberg AL. Muscle protein breakdown and the critical role of the ubiquitin-proteasome pathway in normal and disease states. J Nutri 1999;129:22737.

6. Franch HA, Price SR. Molecular signaling pathways regulating muscle proteolysis during atrophy. Curr Opin Clin Nutr Metab Care 2005; 8:271-5.

7. Lorenz S, Cantor AJ, Rape M, Kuriyan J. Macromolecular juggling by ubiquitylation enzymes. BMC Biol 2013;11:65-76.

8. Neutzner M, Neutzner A. Enzymes of ubiquitination and deubiquitination. Biochem Soc Essays Biochem 2012;52:37-50. 


\section{Hind Limb Suspension, but not Merg1a, Yields $\boldsymbol{U} b r 2$ Expression}

Eur J Trans Myol - Basic Appl Myol 2014; 24 (3): 173-179

9. Hatakeyama S, Nakayama KI. U-box proteins as a new family of ubiquitin ligases. Biochem Biophys Res Comm 2003;302:635-45.

10. Koegl M, Hoppe T, Schlenker S, et al. A novel ubiquitination factor, E4, is involved in multiubiquitin chain assembly. Cell 1999;96:63544.

11. Kwak KS, Zhou X, Solomon V, et al. Regulation of protein catabolism by muscle-specific and cytokine-inducible ubiquitin ligase E3 $\alpha$-II during cancer cachexia. Can Res 2004;64:8193-8.

12. Suzuki T, Varshavsky A. Degradation signals in the lysine-asparagine sequence space. EMBO J 1999;18:6017-26.

13. Varshavsky A. The N-end rule: functions, mysteries, uses. PNAS USA 1996;93:12142-9.

14. Solomon V, Goldberg AL. Importance of the ATP-ubiquitin-proteasome pathway in the degradation of soluble and myofibrillar proteins in rabbit muscle extracts. $J$ Biol Chem 1996;271:26690-7.

15. Bachmair A, Finley D, Varshavsky A. In vivo half-life of a protein is a function of its aminoterminal residue. Science 1986;234:179-86.

16. Solomon V, Lecker SH, Goldberg AL. The N-end rule pathway catalyzes a major fraction of the protein degradation in skeletal muscle. $\mathbf{J}$ Biol Chem 1998;273:25216-22.

17. Kwon YT, Xia Z, Davydov IV, et al. Construction and analysis of mouse strains lacking the ubiquitin ligase UBR1 $(\mathrm{E} 3 \alpha)$ of the N-End Rule pathway. Molec Cell Biol 2001; 21:8007-8021.

18. Varshavsky A, Turner G, Du F, Xie Y. The ubiquitin system and the $\mathrm{N}$-end rule pathway. J Biol Chem 2000; 381:779-89.

19. Xie Y, Varshavsky A. The E2-E3 interaction in the N-end rule pathway: The RING-H2 finger of E3 is required for the synthesis of multiubiquitin chain. EMBO J 1999; 18:6832-6844.

20. Zhang G, Lin RK, Kwon YT, Li YP. Signaling mechanism of tumor cell-induced up-regulation of E3 ubiquitin ligase UBR2. FASEB J 2013;27:2893-901.

21. Curran ME, Splawski I, Timothy KW, et al. A molecular basis for cardiac arrhythmia: herg mutations cause long QT syndrome. Cell 1995;80:795-803.

22. Wang X, Hockerman GH, Green 3rd HW, et al. Merg1a $\mathrm{K}^{+}$channel induces skeletal muscle atrophy by activating the ubiquitin proteasome pathway. FASEB J 2006;20:1531-3.
23. Pond AL, Nedele C, Wang W-H, et al. The MERG1a channel modulates skeletal muscle MuRF1, but not MAFbx, expression. Muscle Nerve 2013; DOI: 10.1002/mus.23924.

24. London B, Trudeau MC, Newton KP, et al. Two isoforms of the mouse Ether-a-go-go-related gene coassemble to form channels with properties similar to the rapidly activating component of the cardiac delayed rectifier $\mathrm{K}+$ current. Circ Res 1997;81:870-8.

25. Taylor JA, Babbs. Optimization of Ectopic Gene Expression in Skeletal Muscle through DNA Transfer by Electrotransfer. BMC Biotechnology 2004;4:11-4.

26. Jones SW, Hill RJ, Krasney PA, et al. Disuse atrophy and exercise rehabilitation in humans profoundly affects the expression of genes associated with the regulation of skeletal muscle mass. FASEB J 2004;18:1025-27.

27. Skurk C, Izumiya $\mathrm{Y}$, Maatz $\mathrm{H}$, et al. The FOXO3a transcription factor regulates cardiac myocyte size downstream of AKT signaling. J Biol Chem 2005;280:20814-23.

28. Dodd SL, Hain B, Senf SM, Judge AR. Hsp27 inhibits IKK $\beta$-induced NF- $\kappa \mathrm{B}$ activity and skeletal muscle atrophy. FASEB J 2009; 23:341534.

29. Wang $\mathrm{H}$, Zhang $\mathrm{Y}$, Cao L,et al. HERG K+ channel, a regulator of tumor cell apoptosis and proliferation. Can Res 2002;62:4843-8.

30. Reed SA, Senf SM, Cornwell EW, et al. Inhibition of IkappaB alpha (IKK $\alpha$ ) or IKKbeta (IKK $\beta$ ) plus forkhead box $\mathrm{O}$ (Foxo) abolishes skeletal muscle atrophy. Biochem Biophy Res Comm 2011;405:491-6.

31. Tasaki T, Mulder LCF, Iwamatsu A, et al. A family of mammalian E3 ubiquitin ligases that contain the UBR box motif and recognize $\mathrm{N}$ degrons. Mol Cell Biol 2005;25:7120-36.

32. Lamothe SM, Zhang S. The serum- and glucocorticoid-inducible kinases SGK1 and SGK3 regulate HERG channel expression via ubiquitin ligase Nedd4-2 and GTPase Rab11. J Biol Chem 2013;288:15075-84.

33. Almilaji A, Munoz C, Elvira B, et al. AMPactivated protein kinase regulates hERG potassium channel. Pflugers Arch 2013; DOI: 10.1007/s00424-013-1299-8.

34. Wang J, Wang $\mathrm{H}$, Zhang $\mathrm{Y}$, et al.Impairment of HERG $\mathrm{K}+$ channel function by tumor necrosis factor- $\alpha$. J Biol Chem 2004; 13289-92. 